OPEN AccESS Freely available online
www.banglajol.info/index.php/JSF
Journal of Science Foundation
January 2019, Vol. 17, No. 1, pp. 1-2
ISSN (Print) 1728-7855
DOI: https://doi.org/10.3329/jsf.v17i1.44861

\title{
Editorial
}

\section{Therapeutic Application of Botulinum Toxin among Patients suffering from Neurological Diseases: Bangladesh Situation}

\begin{abstract}
Selim Shahi ${ }^{1}$
Therapeutic application of botulinum toxin type A has given a dramatic impact on neurologic disorders (Orsini et al., 2015). This bacterial endotoxin is produced by Clostridium botulinum during growth and reproduction. This toxin had been divided into seven serotypes according to the difference in toxin antigenic profiles named as type A, B, C, D, E, F and G. Type A, B, E and F are human toxic types while type C and $\mathrm{D}$ are animal and poultry toxic types.
\end{abstract}

Botulinum toxin acts as the neuromuscular junction to inhibit the release of neuro-transmitter, acetylcholine, presynaptically by fast, specific and irreversible binding to acceptors on presynaptic nerve surface, uptake of toxin into cell vesicle, translocation of toxin into cytosol across vesicle membrane, toxin activates proteolysis which, in turn, blocks the release of acetylcholine. These serve as basis evidence that help develop innovative indications and new therapeutic applications. Botulinum toxin (BT) is currently used in those entities characterized by excessive muscle contraction, including dystonia and spasticity. In addition, BT has been used to control pain associated with increased muscle contraction in dystonia and spasticity.

Neurological disorders that trigger spasticity such as stroke, multiple sclerosis, head trauma, spinal cord trauma, cerebral palsy and some motor neuron diseases like spastic paraparesis, amyotrophic lateral sclerosis which can be managed by applying botulinum toxin (Ney and Joseph 2007). The mechanism of action is complex which mainly acts on terminal neuromuscular junction.

It is very essential for a meticulous planning before giving the injection. Furthermore, it is also very important to calculate the toxin dosages for the individual muscles likely to be injected. A written informed consent from the patient is mandatory before giving the injections. It is advisable to do a video tape about the movements for future reference, and use them as a baseline for comparison to assess for any improvement or side effects (Bentivoglio et al., 2015).

The detailed knowledge about the toxin and its dilution rate is utmost important, as it will remarkably influence the results in the patients. The dilution rates in blepharospasm patients varies from 1.25 units (U)/0.1 ml to $5 \mathrm{U} / 0.1 \mathrm{ml}$ for on a botulinum toxin $\mathrm{A}$ and in co botulinum toxin $\mathrm{A}$, whereas it varies from 10 $\mathrm{U} / 0.1 \mathrm{ml}$ to $20 \mathrm{U} / 0.1 \mathrm{ml}$ for abo botulinum toxin A. The recommended dilutions of on a botulinum toxin A/in co botulinum toxin A for cervical dystonia patients varies from $50 \mathrm{U} / 1 \mathrm{ml}$ to $200 \mathrm{U} / 4 \mathrm{~mL}$ with normal saline. This dosage is also dependent on the volume and number of injection sites desired to achieve the treatment objectives. In general, not more than 50 Units per site and $400 \mathrm{U}$ maximum per sitting, should be administered. A sterile needle of an appropriate length like 27-32 gauge for blepharospasm and 22-24 gauge for cervical dystonia should be used (Intiso 2012).

Localization of the involved muscles with electromyographic (EMG) guidance may be useful, but EMG can only reveal if the muscles are hyperactive or not. The outcome following EMG guided injections were comparable to the manual injections following palpation of muscles. Ultrasound is a new way to localize the muscles to be injected. Various studies have shown the superiority of ultrasound over clinical palpation of muscles. Further injections are guided by the response of the patient to prior injections and the side effects.

\footnotetext{
${ }^{1}$ Dr. Selim Shahi, Associate Professor, Department of Neurology, National Institute of Neurosciences \& Hospital, Sher-E-Bangla Nagar, Agargaon, Dhaka-1207, Bangladesh; Email: drselim.mitford@ gmail.com; Cell no.: +8801712101747
} 
Higher doses are required if the patient has less than 50 to $60.0 \%$ improvement from the previous injection (Tater and Pandey 2018). The toxin is contraindicated in pregnancy and during breast-feeding.

Botulinum toxin injections are generally safe and effective with very few side effects. It is important to note any prior history of bleeding diathesis or a history of blood thinning medications being administered; as the toxin is given intramuscularly, the presence of these conditions can lead to haematoma formation. The toxin can spread to nearby tissues when injected in large doses, rarely leading to weakness of muscles. Also, rare systemic side effects of the toxin that are reported include influenza-like illness, necrotizing fasciitis, gall bladder dysfunction, brachial plexopathy and generalized muscular weakness (Hallett 2017). A subset of patients can develop antibodies against the toxin making them non-responders (Lim and Seet 2010).

In Bangladesh a large number of patients are suffering from neurological disorders which can be treated by botulinum toxin. The toxin is costly and this leads is a big issue for the application among the patients of this country (Dash and Araf 2009). In National Institute of Neurosciences \& Hospital, Dhaka, this therapeutic approach is carried out by a group of well-trained neurologist. This is a referral neurology hospital in Bangladesh. As a member of this group, I am very optimistic regarding the applicability of this toxin among the patients. We have successfully completed a significant number of patients with a good outcome. In near future this success will guide us towards a successful treatment option among the patients.

[Journal of Science Foundation 2019;17(1):1-2]

\section{References}

Bentivoglio AR, Del Grande A, Petracca M, Ialongo T, Ricciardi L. Clinical differences between botulinum neurotoxin type A and B. Toxicon Off J Int Soc Toxinology 2015;107:77-84

Dash SK, Araf MM. Therapeutic application of botulinum toxin in clinical practice. Open Gen Intern Med J. 2009;3:14-9

Hallett M. Mechanism of action of botulinum neurotoxin: Unexpected consequences. Toxicon. 2017 Aug 11.

Intiso D. Therapeutic use of botulinum toxin in neurorehabilitation. Journal of toxicology. 2012;2012

Lim ECH, Seet RCS. Use of botulinum toxin in the neurology clinic. Nat Rev Neurol 2010;6:624-36

Ney JP, Joseph KR. Neurologic uses of botulinum neurotoxin type A. Neuropsychiatric disease and treatment. 2007;3(6):785-98

Orsini M, Leite MA, Chung TM, Bocca W, de Souza JA, de Souza OG, et al. Botulinum neurotoxin type A in neurology: update. Neurology international. 2015;7(2):14

Tater P, Pandey S. Botulinum toxin in movement disorders. Neurology India. 2018;66(7):79-89 